\title{
La estética del pastiche postmoderno. Una lectura crítica de la teoría de Fredric Jameson
}

\section{Postmodern pastiche aesthetics. A critical reading of Fredric Jameson's theory}

\author{
INMACULADA MURCIA SERRANO \\ Departamento de Estética e Historia de la Filosofía \\ Universidad de Sevilla
}

Recibido: 19-05-2009 Aprobado definitivamente: 23-10-2009

\section{RESUMEN}

En el presente artículo se pretende sacar a la luz los presupuestos filosóficos e ideológicos que subyacen a la teoría del pastiche postmoderno del pensador norteamericano Fredric Jameson. Pese a que las descripciones que se encuentran en La lógica cultural del capitalismo tardio son breves y escuetas, los fundamentos marxistas y estructuralistas que las ahorman ayudan a entenderla. En paralelo, se explica una de sus tesis más desconocidas, la relativa a la llamada «película nostálgica», y se explica su actitud ante otras manifestaciones artísticas postmodernas como la arquitectura historicista.

PALABRAS CLAVE

POSTMODERNISMO, PASTICHE, FREDRIC JAMESON, ARQUITECTURA POSTMODERNA, PELÍCULA NOSTÁLGICA

\section{ABSTRACT}

This paper intends to clarify the philosophical and ideological backgrounds that underlie the North American thinker Fredric Jameson's theory of the postmodern pastiche. Despite the fact that the descriptions provided in Postmodernisms, Or the Cultural Logic of Capitalism are brief and succinct, the Marxist and Structuralist foundations that form them can help understand this 
theory. In parallel, we explain one of his lesser known theses, the so called «nostalgic movie», and his attitude towards other artistic postmodern manifestations as the historicist architecture. KEYWORDS POSTMODERNISM, PASTICHE, FREDRIC JAMESON, POSTMODERN ARCHITECTURE, NOSTALGIC MOVIE

\section{CARACTERIZACIÓN DEL PASTICHE EN LA OBRA DE FREDRIC JAMESON}

«EL MODO MÁS SEGURO DE COMPRENDER el concepto de lo postmoderno es considerarlo como un intento de pensar históricamente el presente en una época que ha olvidado cómo se piensa históricamente». ${ }^{1}$ Con esta frase comienza el ensayo de Fredric Jameson La lógica cultural del capitalismo tardío (1984), ${ }^{2}$ un texto de referencia para los estudios sobre la postmodernidad en el que se sugieren numerosas intuiciones acerca de la práctica o la estética del pastiche. ${ }^{3}$ A ojos de este autor, el pastiche postmoderno se origina cuando desaparece u olvidamos la historia. Determinar cómo y en función de qué presupuestos se puede establecer esta relación constituye el objetivo del presente artículo.

Jameson considera el pastiche como la principal consecuencia que se deriva del derrumbe de la «ideología del estilo», la fuente esencial de invención e innovación artísticas durante la modernidad. El autor asocia este fenómeno con la desaparición o descentramiento postmodernos del sujeto, que habrían provocado la ruina de aquella otra estética de la expresión que incentivaba la búsqueda de un estilo personal e identificable: «La desaparición del sujeto individual, y su consecuencia formal de la creciente disipación del estilo personal, engendran la práctica casi universal de lo que se puede llamar "pastiche"». ${ }^{4}$ Éste se ha de caracterizar entonces, no por abrir nuevas sendas estilísticamente innovadoras, sino por volver la mirada hacia «las voces almacenadas en el museo imaginario

1 F. Jameson, Teorías de la postmodernidad, tr. C. Montolío Nicholson y R. Del Castillo. Madrid: Trotta, 1996, p. 9.

2 F. Jameson, «Postmodernism, or the Cultural Logic of Capitalism», New Left Review, $\mathrm{n}^{\circ} 146,1984$, pp. 53-92.

3 Jameson toma el término de la novela Dr. Faustus de Thomas Mann, quien, a su vez, lo recoge de las obras dedicadas por Theodor W. Adorno a la experimentación musical avanzada de Arnold Schönberg e Igor Stravinsky. Thomas Mann usa el término en los capítulos XXII y XXXIV de su novela para hablar de la relación entre esteticismo y barbarie presentes en la composición sobre el Apocalipsis de su protagonista, Adrián Leverkühn. Véase T. Mann, Doctor Faustus, trad. E. Xamar. Barcelona: Pocket Edhasa, 1998, p. 433. En Los orígenes del Doctor Faustus. La novela de una novela, se describen los avatares de la redacción de la obra y se pone énfasis en la influencia que sobre él ejerció Sobre la filosofía de la música moderna de Adorno. Véase T. Mann, Los orígenes del Doctor Faustus. La novela de una novela, tr. C. Gauger. Madrid: Alianza, 1988.

4 F. Jameson, Teorías de la postmodernidad, op.cit., p. 37. 
de la cultura global» y practicar una especie de «canibalización aleatoria de todos los estilos del pasado». Ello traería consigo la revalorización de lo «neo» (neohistoricismo, neobarroco, neogótico, etc. ${ }^{5}$ ).

Desde un punto de vista más general, Jameson concibe el pastiche como un fenómeno asociado al deseo humano de habitar en un mundo transformado en imágenes, en pseudoacontecimientos o en espectáculo. Su estrecha relación con las simulaciones se debe también a que el pastiche ha nacido en el seno de una cultura regida por las leyes del capitalismo que generaliza el valor de cambio en detrimento del valor de uso, y que, como diría Guy Debord, a quien Jameson menciona explícitamente, hace que la imagen se convierta «en la forma final de la reificación de la mercancía». ${ }^{6}$

Una característica más particulariza al pastiche en el texto de Jameson: su diferencia con respecto a la parodia. $\mathrm{Si}$, como práctica moderna, ${ }^{7}$ ésta consistía en desviarse lingüísticamente de una norma que, por negación, se reafirmaba, el pastiche, como práctica ejercida en un contexto lingüísticamente fragmentado, habría dejado de tener tal pretensión. ${ }^{8}$ Dice Jameson que la parodia exhibía, exagerándolas, las rarezas de la norma contra la que se enfrentaba; ${ }^{9}$ por el contrario, el pastiche, puesto que se opone a una norma que ya no es única, frustra las virtualidades de la primera, carece de humor y se transforma en una «parodia vacía» o en «una estatua ciega». ${ }^{10}$

\section{LA SORDERA HISTÓRICA}

Para llevar a cabo una lectura crítica de esta aproximación al pastiche postmoderno, hay que comenzar analizando las bases filosóficas de la teoría, en concreto, las que se refieren a la relación que los postmodernos mantienen con la historia.

Terry Eagleton ha dicho que el postmodernismo se caracteriza por tomar conciencia de que la Historia no es más que un asunto teleológico que depende de la creencia en que el mundo se mueve hacia cierto objetivo predeterminado que le es inmanente y que provee de sentido a la dinámica de su despliegue. ${ }^{11}$

5 Ibid., pp. 38-39.

6 Ibid.

7 El autor cita como ejemplos a Faulkner, Lawrence, Wallace Stevens, Mahler e incluso a Heidegger.

8 F. Jameson, Teorías de la postmodernidad, op. cit. p. 38.

9 «Todo esto da la impresión de ser algo idiosincrásico, ya que se desvía sin ambages de una norma que se reafirma (no siempre con hostilidad) imitando sistemáticamente sus excentricidades características». Ibid., p. 38.

10 Ibid.

11 Véase T. Eagleton, Las ilusiones del postmodernismo. Barcelona: Paidós, 1997, p. 77. 
Esta concepción, de raigambre judeocristiana, habría sido desautorizada en la postmodernidad dando al traste con uno de los grandes relatos de emancipación -el del Progreso-, y poniendo entre interrogantes el sentido mismo de la historia.

Frederic Jameson es uno de los autores que más tiene en cuenta la descreencia postmoderna en el sentido histórico. No lleva a cabo su negativa asumiendo la teoría de Lyotard que describe la postmodernidad como el final de la creencia en los metarrelatos de legitimación, ${ }^{12}$ puesto que considera que dicha teoría entraña también un metarrelato. ${ }^{13}$ En contraposición, prefiere considerar la desaparición del sentido histórico como una consecuencia de la «dominante cultural» del postmodernismo, que, en virtud de su creciente tendencia a la espectacularización, transforma la visión en profundidad de la Historia en mera formalización o «distracción» postmoderna, según denominación de Walter Benjamin. La nueva dominante cultural convertiría a la Historia en una visión epidérmica del pasado de la que se sustrae la mirada en escorzo sobre la realidad. Por lo tanto, la postmodernidad no traería consigo una descreencia en los metarrelatos de legitimación, sino una trivialización de los mismos en aras de su estetización o conversión en mero espectáculo. La postmodernidad, como dice el autor, «sólo registra las propias variaciones, y sabe de sobra que los contenidos son también meras imágenes». ${ }^{14}$

Habría que precisar que la negativa a secundar la tesis de Lyotard obedece a que Jameson es un pensador (neo)marxista, es decir, que admite al menos uno de los grandes relatos en teoría deslegitimados. ${ }^{15} \mathrm{Y}$ esto es importante resaltarlo, no sólo porque sirve para entender su aproximación al pastiche, tan mediatizada por la perspectiva que adopta ante el capitalismo multinacional, sino también porque, en cierto sentido, supone incurrir en una contradicción con los propios presupuestos de su pensamiento, que se encaminan, según The political unconscious. Narrative as a socially symbolic act, ${ }^{16}$ a descubrir los mensajes políticos que encubren los textos literarios o creativos. A la hora de teorizar sobre el pastiche, Jameson no pone en práctica esa crítica de la crítica que aplica con otros autores, y hasta tal punto es así que lo que podría haber

12 Véase J-F. Lyotard, La condición postmoderna, tr. Manuel Antonio Rato. Madrid: Cátedra, 1994.

13 Véase F. Jameson, Documentos de cultural, documentos de barbarie. La narrativa como acto socialmente simbólico, tr. Tomás Segovia. Madrid: Visor, 1989.

14 F. Jameson, Teorías de la postmodernidad, op. cit., p. 9.

15 Véase, para este tema J.C. Fernández Serrato: «Fredric Jameson y el inconsciente político de la Postmodernidad» (http://www.uruguaypiensa.org.uy/noticia_14_1.html).

16 F. Jameson, Documentos de cultural, documentos de barbarie. La narrativa como acto socialmente simbólico, op. cit. 
de reflexión estética termina siendo engullido por un análisis mediatizado ideológicamente.

Su aproximación a esta práctica artística depende directamente de la idea de que la postmodernidad ha olvidado cómo se piensa la historia al tiempo que la ha convertido en algo superficial. No por casualidad, uno de los rasgos que atribuye al pastiche es su rechazo a la novedad estética de raigambre modernista, que se ve reemplazada por una vuelta al pasado carente de lógica y jerarquización. Es comprensible que Jameson cite el libro The Italian Trans-avantgarde de Achille Bonito Oliva, ${ }^{17}$ en el que se defiende en la misma línea que el arte italiano de la transvanguardia refleja una crisis en la mentalidad evolucionista o darwinista del vanguardismo que señala, a su vez, a la crisis general del sistema. ${ }^{18}$ Para Bonito Oliva, la manera de entrever los movimientos que tienen lugar desde esa fecha en el ámbito artístico no puede seguir siendo la basada en el modelo historicista de la continuidad, sino la posthistórica que habla en términos de «catástrofe» y que explica por qué los artistas transitan por caminos no preestablecidos históricamente inmiscuyéndose incluso en los límites de la vanguardia y su tradición. ${ }^{19}$

El ejemplo de la transvanguardia italiana respalda a Jameson en su intento de hacer eclosionar el relato tradicional del arte de corte continuista o darwinista para sustituirlo por otro que instala las prácticas en una especie de vidriera atemporal en la que conviven caracteres estilísticos de distintas épocas. De alguna manera, entre los presupuestos de su pensamiento se encuentra entonces la idea de que existe una especie de causalidad entre los caracteres generales de la época postmoderna y sus productos artísticos o culturales. Hemos de comenzar diciendo que el primero de estos términos -la «sordera histórica»-, tiene influencia directa del pensador y artista francés, Guy Debord.

\section{Guy DEBORD Y EL «PRESENTE PERPETUO» DEL ESPECTÁCULO}

Recordemos que el núcleo del pensamiento y de la propuesta artística situacionista que, alimentada del programa anti-esteticista de las vanguardias, buscaba crear situaciones para evitar la reproducción, giraba en torno a la idea de que en nuestro tiempo preferiríamos la imagen a la cosa, la copia al original. Según Guy Debord, la contemplación pasiva de imágenes elegidas por otros

17 A. Bonito Oliva, The Italian Trans-avantgarde, La Trasvanguardia italiana, Milano: Giancarlo Polito Editore, 1983.

18 «Today the crisis in art in sensu stricto means the crisis in the evolution of artistic language -the crisis in the avant-garde's Darwinistic and Evolutionary mentality. This critical moment is overturned in terms of new operability by artistic generation of the 70». A. Bonito Oliva, op. cit. p. 7.

19 Ibid., p. 13. 
estaba sustituyendo la experimentación en primera persona de los acontecimientos. ${ }^{20}$ Partiendo de esta convicción, el autor actualiza en La sociéte du spectacle $(1967)^{21}$ el marxismo clásico a través del concepto de «espectáculo», entendido como la nueva metamorfosis de la alienación capitalista y religiosa. ${ }^{22} \mathrm{Si}$ en una primera fase de la evolución histórica de la alienación, el «ser» se degrada en «tener», en una segunda, que se corresponde con la aparición de la sociedad del espectáculo, el «tener» se degrada en «parecer». El «parecer» del espectáculo, en su continua tendencia hacia la abstracción u objetivación marxistas, se torna alienante y fetichista ${ }^{23}$ porque, una vez objetivado y mercantilizado, una vez invertidos los términos sujeto-objeto tanto en su forma concentrada como en la difusa ${ }^{24}$ acapara toda la comunicación, convierte a los individuos en predicados de la mercancía espectacular, y se vuelve enteramente unilateral y monotemático. ${ }^{25}$ Gracias a la desaforada renovación tecnológica y a la fusión económico-estatal, el espectáculo afianza el secreto generalizado, la falsedad sin réplica y, lo que aquí más nos interesa, la inmersión en un «perpetuo presente». ${ }^{26}$ El resultado no puede ser otro que la conversión de la realidad en imagen, la paralización esclerotizada de nuestra vida entendida ya como una auténtica Weltanschauung. ${ }^{27}$ Debord no concibe el espectáculo como un mero añadido al mundo, sino que, en tanto abstracción, de hecho, la «suma abstracción», ${ }^{28}$ lo

20 Véase G. Debord, La sociedad del espectáculo, tr. J. L. Pardo. Valencia: Pre-textos, $2008, \S 1$ y $\$ 30$. Véase también A. Jappe, Guy Debord, tr. L. A. Bredlow. Barcelona: Anagrama, 1998 , p. 20.

21 Apareció por primera vez en la editorial Buchet-Chastel de París en 1967.

22 G. Debord, La sociedad del espectáculo, op. cit., §20, p. 44.

23 Según Debord, el principio del fetichismo de la mercancía -la dominación de la sociedad a manos de «cosas suprasensibles al par que sensibles»- se realiza absolutamente en el espectáculo, en el cual el mundo sensible es sustituido por una selección de imágenes que existen por encima de él, y que aparecen al mismo tiempo como lo sensible por excelencia. Ibid., §36, p. 52 .

24 En 1967, Guy Debord distinguía todavía dos formas sucesivas y rivales del poder espectacular: la concentrada, que daba prioridad a la ideología que se aglutina en torno al poder dictatorial; y la difusa, que tenía que ver con la americanización del mundo. Algunos años después, se vio obligado a rectificar su teoría y publicó sus Comentarios de la sociedad del espectáculo, en donde hablaba de una nueva forma, fruto de la combinación de las anteriores, que denominaba lo espectacular integrado y que tendía a imponerse mundialmente. Véase $\mathrm{G}$. Debord, Comentarios sobre la sociedad del espectáculo, tr. C. López y J. R. Capella. Barcelona: Anagrama, 1990, §IV.

25 A. Jappe, op. cit., pp. 20-21.

26 G. Debord, La sociedad del espectáculo, op. cit. §126,pp. 117-118. También G. Debord, Comentarios sobre la sociedad del espectáculo, op. cit., §V, p. 23.

27 G. Debord, La sociedad del espectáculo, op. cit., §5.

28 Ibid., §19, pp. 40-49. 
entiende como algo que se apodera para sus propios fines de toda la actividad social y cuyo alcance es tan grande que incorpora dentro de sí a las demás alienaciones..$^{29}$ Como consecuencia de su enorme difusión, la realidad es sustituida por su imagen, $y$, finalmente, la imagen acaba tornándose real. ${ }^{30}$

Según el pensador y artista francés, la primera intención de la dominación espectacular es por lo demás ocultar el conocimiento histórico. ${ }^{31}$ Ello, naturalmente, ha de tener consecuencias para la comprensión contemporánea del concepto de historia: si tradicionalmente ésta se entendía como la medida de la novedad, para Debord, lo que está ocurriendo ahora es que el espectáculo, que sobrevive gracias a de la venta continuada de novedades, hace desaparecer lo histórico porque necesita eliminar el medio de calibrarlo: sólo si relativiza los criterios, el espectáculo puede garantizar una venta continuada de pseudoacontecimientos basada en la perseverancia de una instantaneidad que se sigue de otra y que es la característica principal del llamado tiempo espectacular. Los criterios históricos, la medida que antaño proporcionaba la historia, son así sustituidos por una nueva ley regida por el secreto y según la cual vivimos en una especie de eternidad ruidosa en la que resplandece sin interrupción lo insignificante. ${ }^{32}$ La vida individual se ve entonces desprovista de historia, puesto que los pseudoacontecimientos que difunde el espectáculo no se corresponden con los que han sido vividos por los espectadores; por inversión, lo que sí ha sido vivido, al ser separado del tiempo espectacular, deja de tener lenguaje en el que consignarse y permanece incomprendido y olvidado. ${ }^{33} \mathrm{El}$ espectáculo separa al individuo de su propia temporalidad y le hace atravesar un presente ajeno, una alienación controlada que petrifica las posibilidades y los riesgos de la, hegelianamente hablando, alienación viva en el tiempo. ${ }^{34}$

Es más que evidente que el texto de Jameson está mediatizado por la lectura de la obra de Guy Debord, tanto en lo que concierne a la conversión de la vida en espectáculo y de la historia en imagen, como en lo que tiene que ver con la transformación del espectáculo en mercancía. De cara a desenmascarar las fuentes ideológicas que encubre su teoría del pastiche, de estas características nos interesa una que podría haber influido en el carácter caleidoscópico que aprecia en él: la de que, una vez que el espectáculo como forma-mercancía se torna alienante, abstracto y siempre igual, el tiempo se detiene, y la vida falsamente vivida se instala en un presente imperecedero donde sólo habla lo insignificante.

29 A. Jappe, op. cit., p. 27.

30 Ibid., p. 21.

31 G. Debord, Comentarios sobre la sociedad del espectáculo, op. cit., §VI, p.25

32 G. Debord, La sociedad del espectáculo, op. cit., §158, p. 138. Véase también G. Debord, Comentarios sobre la sociedad del espectáculo, op. cit., §VI, pp. 26-27.

33 G. Debord, La sociedad del espectáculo, op. cit., §157, pp. 137-138.

34 Ibid., $\$ 161$. 
Sólo teniendo en cuenta la influencia de Debord, puede entenderse la afirmación de Jameson acerca de la práctica histórica postmoderna como «sorda» a la historia, como un visionado del pasado estrictamente estético que nos invita a vivir en un «presente perpetuo» sin fondo, jerarquía y antigüedad. ${ }^{35}$

La superficialidad histórica con la que Jameson relaciona el pastiche está mediatizada, no sólo por la espectacularización debordiana de la vida, sino también, como consecuencia directa, por su propia tesis de que la postmodernidad está más determinada espacial que temporalmente, lo que implica ipso facto la carencia de profundidad. La espacialización o desfondamiento del tiempo trae consigo que todo se torne apariencia y que los elementos artísticos recogidos del pasado se ubiquen en una especie de cristalera temporalmente plana. Los ejemplos artísticos que Jameson menciona a propósito del modelo estético de la esquizofrenia lacaniana y entre los que se encuentran las videoinstalaciones de Nam June Paik deben entenderse a luz de estas implicaciones. ${ }^{36}$

Pero la influencia de Debord va más allá. La teoría del pastiche está mediatizada ideológicamente por la crítica cultural sobre la que se asienta la obra del artista francés y, en general, por la que practica, desde mediados del siglo $\mathrm{XX}$, el pensamiento filosófico de corte marxista como el frankfurtiano; tanto es así que esa ideología es la que subyace a la distinción que Jameson establece entre pastiche y parodia.

\section{PASTICHE, PARODIA Y COLLAGE}

Empecemos con una comparación. Se puede decir que la distinción histórica entre pastiche y parodia es paralela a la que otros autores han establecido entre pastiche y collage. En ambos casos se da por supuesto que el collage $-\mathrm{y}$ en el caso de Jameson, la parodia-, constituyen prácticas artísticas modernas, mientras que el pastiche se correspondería más bien con la postmodernidad.

Según Monica Kjellman-Chapin, el punto de inflexión que determina la inclusión del prefijo post a lo que tradicionalmente se consideraba un collage lo establece Rosalind Krauss al afirmar que Pablo Picasso estaba produciendo pastiches entre 1916 y 1924, un periodo que se enmarca en los límites temporales del modernismo. ${ }^{37}$ La historia no es exactamente así, puesto que lo que hace Rosalind Krauss en The Picasso Paper es citar una crítica que Picasso había recibido de Roger Allard a propósito de la exposición que organizó en 1919 para su nuevo marchand, Paul Rosenberg, y que era la primera muestra individual que organizaba en los últimos trece años. Fue Allard y no Krauss

35 F. Jameson, Teorías de la postmodernidad, op. cit., p. 11.

36 Ibid., pp. 51-55.

37 M. Kjellman-Chapin, «Traces, Layers and Palimpsests: The Dialogics of Collage and Pastiche», Kunsthistorisk Tidskrift/Journal of Art History, 2006, 75:2; pp. 86-99. 
quien por primera vez escribió, en Le Nouveau Spectateur, que lo que había hecho Picasso no eran más que pastiches históricos en los que estaba recogido todo, «incluyendo a Leonardo, Durero, Le Nain, Ingres, Van Gogh, Cézanne: sí, todo... excepto Picasso». ${ }^{38}$ Lo que afirma Krauss a continuación es que aquel comentario terminó perjudicando a la totalidad del cubismo, máxime cuando consiguió pervivir durante años hasta llegar incluso a Gérard Genette, quien consideraría en Palimpsestes que el pastiche constituía la matriz en la que se gestaba la obra de Picasso. ${ }^{39}$

En cualquier caso, Krauss hizo efectivamente suya la crítica de Allard, ${ }^{40}$ lo que terminó suscitando la reacción de otros autores que se negaban a calificar de pastiche la obra de un artista como Picasso. Según Monica Kjellman-Chapin, ello terminaría favoreciendo esa tendencia, hoy dominante, que se empeña en distinguir el collage como algo moderno y con unos juicios de valor asociados de carácter positivo, y el pastiche como algo postmoderno y con unos juicios de valor indiscutiblemente negativos. Como ella misma ha dejado escrito, en esta distinción hay implícitos numerosos prejuicios que tienen que ver, no con las características formales del collage o el pastiche, sino con el uso coloquial, eminentemente peyorativo, que se le ha atribuido al segundo de los términos. La consecuencia es que, mientras que en la definición de collage se presupone que el artista toma elementos extraños y crea algo con ellos modificándoles el sentido y otorgándoles una identidad, el pasticheur es considerado como un imitador y casi como un parásito, al tiempo que su producto es percibido como carente de identidad y de mensaje. A diferencia del artista que se dedica al collage, se percibe que el pasticheur crea un «batiburrillo» (hodgepodge) de cosas del que sólo puede salir una especie de «potaje» (stew) estético, es decir, algo relacionado con el plagio, lo fraudulento y lo tramposo. ${ }^{41}$

38 Citado por R. Krauss, Los papeles de Picasso, tr. M. Reilly de Fayard. Barcelona: Gedisa, 1999, p. 97.

39 R. Krauss, op. cit. p. 97. Véase también G. Gennet, Palimpsestes. Paris: Senil, 1982, p. 144.

40 «Entre 1916 y 1924, a medida que el pastiche se iba convirtiendo en el medo con el que ejercía su práctica, Picasso realizó una obra cada vez más fatua -afectada, decorativa, vacía-que parece irreconciliable con el rigor formal del cubismo y, con todo, dado el ejemplo sin par de ese brillo anterior, una obra que de algún modo tiene que brotar de su propia lógica interna y no de un conjunto de circunstancias externas. La lógica del síntoma sería pues análoga y perjudicial, pero no reivindicaría al cubismo como el feliz acicate de Picasso imitando a Braque. Antes bien, buscaría la etiología del pastiche, las condiciones internas para su comienzo. Si se considera el pastiche como algo sintomático -como una ruptura estética, por así decirlo-formaría su proyecto de explicación histórica según algo similar a un modelo médico. Pero no una epidemiología, sino más bien una psicopatología: algo así como la psicopatología de la vida práctica del artista». R. Krauss, op. cit., p. 107.

41 M. Kjellman-Chapin, loc. cit. 
Para Monica Kjellman-Chapin, dicha diferenciación carece de lógica porque está basada en prejuicios y porque desestima el hecho de que las analogías que mantienen estructuralmente como ejercicios de parataxis (es decir, de colocación de cláusulas o frases unas tras otras sin coordinación o subordinación) convierten a los collages y a los pastiches en producciones formalmente semejantes. Lo mismo opina Margaret A. Rose, quien recuerda, además, que el pastiche ha sido un instrumento utilizado en otras épocas artísticas del pasado y no exclusivo de la postmodernidad. ${ }^{42}$ La propia Rosalind Krauss se da cuenta del prejuicio que anima a unos a calificar de pastiches las obras del período mencionado de Picasso, mientras que otros, habida cuenta de la importancia histórica del artista, prefieren buscar rodeos lingüísticos para nombrarlas: «Quienes proponen tal interpretación no dan a esto el nombre de pastiche, sino más bien de "acceso" que Picasso ha ganado, con paciencia y legitimidad, al museé imaginaire». ${ }^{43}$ Lo que estas autoras pretenden decir es, en suma, que, en tanto parataxis, el llamado pastiche como el collage emplean, en realidad, las mismas técnicas, contienen una misma densidad alusiva y ponen en juego conexiones ilógicas entre objetos, imágenes o ideas. Ello significa que la diferencia establecida entre collage y pastiche carece, en buena medida, de justificación.

Si menciono todo esto es porque algo parecido se puede advertir con respecto a la diferencia que Jameson establece entre parodia y pastiche, aunque en su caso los prejuicios que le empujan a distinguirlas tienen que ver con otros presupuestos. Como se puede apreciar en su ensayo, la parodia parece estéticamente mejor, mientras que el pastiche, como «parodia vacía» o «estatua ciega», termina representando el signo más cabal de la mediocridad estética tardocapitalista, que es fruto de una sociedad aletargada por el dominio de la cultura mediática en el sentido debordiano y frankfurtiano del término. La cultura de masas, que actuaría como impulsora del pastiche, se presenta así como algo incompatible con la creatividad. Lo que le ocurre a Jameson con el pastiche es parecido a lo que Calinescu ha estudiado respecto a la dialéctica moderno/ postmoderno desde un punto de vista más general: como afirma en uno de sus más conocidos libros, tanto el rechazo «conservador» al postmodernismo, representado, por ejemplo, por Peter Greenberg, como la identificación neo-marxista «radical» del postmodernismo con el consumismo cultural, en la que podemos incluir a Jameson, coinciden en entender el modernismo como una especie de «héroe», bien por su batalla estética contra el mal gusto burgués, bien por su subversión del orden cultural capitalista. En ambos casos, el postmodernismo

42 M.A. Rose, «Post-modern Pastiche», British Journal of Aesthetics, vol.31, $\mathrm{n}^{\circ} 1$, January 1991, p. 29.

43 R. Krauss, op. cit., p. 98. 
aparece como una «relajación» de los estándares críticos, políticos y estéticos del modernismo. ${ }^{44}$

La cuestión es que esa actitud negativa que el filósofo norteamericano exterioriza ante la «relajación» estética del pastiche cae por su propio peso si es cierta la tesis que David Banash ha sostenido en su artículo «From Advertising to the Avant-Garde: Rethinking the Invention of Collage». ${ }^{45}$ En este texto, el autor enlaza los orígenes del collage, no del pastiche, precisamente con el lenguaje de los medios de comunicación y de la cultura comercial emergente en paralelo con las innovaciones de la vanguardia y el modernismo. Desde su punto de vista, la ubicuidad de los espectáculos de los mass media y de las tipografías y formas visuales de la publicidad habría proveído el contexto, la inspiración y los significados técnicos que requería el collage del siglo XX. $\mathrm{Su}$ tesis es controvertida porque, como él mismo explica, para los críticos formalistas y para los teóricos más comprometidos con la vanguardia, el collage nace al margen de los medios, en tanto en cuanto su origen se encuentra en la personalidad creativa de un artista en particular, de nuevo Pablo Picasso, quien, para inventarlo, habría dirigido su interés exclusivamente hacia la crítica del ilusionismo pictórico de cariz renacentista. Además, influidos -como Jameson-, por la Escuela de Frankfurt, los críticos formalistas comparten con sus representantes el prejuicio de que la industria cultural no produce más que obras en las que se echa en falta unidad y conexión. Enfrentándose por tanto a una idea comúnmente aceptada, Banasch defiende que localizar la invención del collage solamente en la obra de Picasso o de Braque significa minusvalorar la forma en que en ello están implicadas las relaciones que se estaban produciendo en aquel momento entre el arte serio y el popular.

Si es cierta esta tesis, puestos a hablar de la influencia de los medios de comunicación en la creatividad artística contemporánea, tendríamos que remontarnos, no tanto al pastiche, cuanto al mismísimo collage, esa práctica moderna que nadie dudaría en calificar de artística. Y si es así, entonces hay que relativizar también la importancia que Jameson atribuye a la dependencia del pastiche de la cultura de masas y, sobre todo, plantear que esas conexiones no tienen por qué ser sinónimas de mediocridad estética o vulgaridad.

44 M. Calinescu, Cinco caras de la modernidad. Modernismo, vanguardia, decadencia, Kitsch, postmodernismo, tr. F. Rodríguez Martín. Madrid: Tecnos, 2003, p. 287.

45 D. Banash, «From Advertising to the Avant-Garde: Rethinking the Invention of Collage», Postmodern Culture, 2004, (internet). 


\section{LA ÚNICA HISTORICIDAD POSIBLE: LA «PELÍCULA NOSTÁLGICA» COMO PASTICHE PÚBLICO}

Conviene reparar en una idea que se encuentra en el ensayo de Jameson y que debe ser aclarada por su interés para los objetivos de este artículo. Se trata de una especie de paradoja respecto a lo comentado más arriba, pues alude al curioso fenómeno de que, en una época desmemoriada por la espectacularización de la vida, se haya reelaborado una especie de historicismo «omnipresente, omnívoro y libidinal», que puede sintetizarse con un único término: la nostalgia. A este respecto, Jameson distingue entre una práctica artística estrictamente postmoderna, la arquitectura historicista, que parece escapar a esta otra modalidad del pseudohistoricismo, y otra cinematográfica, la «película nostálgica», que constituiría su mejor ilustración.

Hay que precisar en este momento que las distinciones y los ejemplos que Jameson utiliza se sostienen en ocasiones sobre descripciones resbaladizas, tan sutiles en algunos casos que el lector ha de hacer un esfuerzo conspicuo para apreciarlas.$^{46}$ Ello hace enormemente difícil explicar los ejemplos sin incurrir en el mismo error. La distinción entre arquitectura historicista y película nostálgica es un bueno ejemplo de ello.

Según el autor, la llamada película nostálgica, cuyo origen se encuentra en American Graffiti (George Lucas, 1973) y su final en Rumble Fish (Francis Ford Coppola, 1983), constituye una especie de proyección del pastiche postmoderno hacia las esferas pública y social. Es posible definirla como aquella que, ambientada en épocas pasadas y pretendiendo rememorar un ayer percibido como irremediablemente perdido, evoca estética o estilísticamente la historia con la pretensión de recuperarla de una forma meramente connotativa. Se trata de un cine nostálgico y no histórico porque la antigüedad que rezuma sólo está sugerida. A diferencia del género histórico, la película nostálgica se limitaría a lanzar un guiño de complicidad hacia el pasado para transmitir la idea de que ha terminado para siempre y de que de él sólo nos queda el recuerdo estereotipado por el imaginario colectivo de sus caracteres estéticos, lo que para Jameson significa de lo meramente superficial, o sea, de lo único para lo que está capacitada la práctica historiográfica postmoderna y su producto el pastiche. La película nostálgica representaría entonces el ejemplo más excelso de esa sordera histórica postmoderna que, incapaz de profundizar en los acontecimientos del pasado, se contenta con rememorarlos a través de la simple connotación.

Para el filósofo norteamericano, esta particularidad trae consigo una consecuencia interesante. La carencia postmoderna de sentido histórico obliga al

46 «Uno puede también observar que Jameson no consigue citar ningún ejemplo concreto de cómo puede realmente reforzar una obra de arte postmoderna la lógica cultural del capitalismo tardío». M. Calinescu, op. cit., p. 286. 
cine nostálgico a dirigirse al pasado a través de lo más anti-histórico que existe, la moda, asociada a la ideología consumista de la generación y al imperio debordiano de la imagen. ${ }^{47}$ Por ejemplo, es la imagen compartida del pasado y no el pasado como tal, la que dota a este tipo de cine de connotaciones históricas susceptibles de ser reconocidas por todos. Jameson reconoce que esta idea se la debe a Roland Barthes, quien entre 1954 y 1956 elaboró una teoría que se encuentra en Mythologies (1957) ${ }^{48}$ y que explica, desde el análisis crítico del lenguaje de la cultura de masas, el mecanismo a través del cual una sociedad elabora sus mitologías contemporáneas.

Influenciado por Saussure e inaugurando con ello el análisis semiológico, en el libro Mitologías, Roland Barthes analizaba, efectivamente, algunos mitos de la vida cotidiana francesa convencido de que era necesario poner de manifiesto el abuso ideológico que se encontraba oculto en lo que socialmente percibíamos como evidente-por-sí-mismo y que había hecho que se confundieran naturaleza e historia en el relato de nuestra actualidad. ${ }^{49}$ Descubrió así que el concepto de mito, entendido como lenguaje o, más bien, como habla socialmente compartida, daba cuenta de esas falsas evidencias y, para lo que aquí nos interesa, que el cine tenía en ello mucho que ver. ${ }^{50}$

Varios de los análisis que se encuentran en la obra de Barthes tratan precisamente de películas de género histórico (incluibles en la denominación de «película nostálgica» de Jameson), como Julio César de Mankiewicz. Barthes explica cómo se gesta en este caso la imagen o el mito de «los romanos en el cine», cuyas características estéticas, estereotipadas por la industria cinematográfica, podrían ser enumeradas sin disentir por cualquiera de nosotros. Entre ellas se encontrarían el sudor ininterrumpido de los personajes, que simboliza su moral, o el flequillo de la frente que, repetido hasta la saciedad, termina atribuyendo a los caracteres la connotación buscada de «romanidad». Para Barthes, esos elementos se convierten en $\operatorname{signos}^{51}$ que garantizan al espectador la certidumbre y el reconocimiento de que nos encontramos en la Roma clásica. ${ }^{52}$ La película en cuestión puede tratar entonces asuntos no necesariamente históricos sin perder por ello toda su parafernalia pseudohistoricista: «Los actores hablan, actúan, se torturan, debaten cuestiones "universales", sin perder nada de su verosimilitud histórica gracias a ese emblema extendido sobre la frente». ${ }^{53}$

47 F. Jameson, Teorías de la postmodernidad, op. cit., p. 40.

48 R. Barthes, Mythologies, Paris: Editions du Seuil, 1957. Existe traducción al castellano con el título Mitologías, tr. Héctor Schmucher, Madrid: Siglo XXI, 1991.

49 Ibid., p. 8.

50 Ibid., p. 200.

51 Ibid., p. 28.

52 Ibid., p. 209.

53 Ibid., p. 28. 
Este tipo de signos se encuentran, según Barthes, en un lugar intermedio entre los intelectuales (como los que utiliza el teatro chino cuando usa una bandera, por ejemplo, para significar todo un regimiento), y los desarraigados o continuamente reinventados (y que los ejemplifica el arte de Stanislavski). El signo intermediario que representa el «flequillo de la romanidad» designaría, en contraposición, un «espectáculo degradado», en palabras de Barthes, «que tanto teme a la verdad ingenua como al artificio total». Su carácter «bastardo», ni intelectual ni visceral, hace que sea pretencioso al tiempo que equívocamente «natural». ${ }^{54}$ Según el autor, ello es criticable porque el mito, como sistema de comunicación, ha de tener siempre un fundamento histórico, ${ }^{55} \mathrm{y}$, para lo que a Jameson y a nosotros nos interesa, porque, pese a que encierra cierto contenido, éste deviene siempre forma, lo que quiere decir que su supuesto sentido histórico es tan vago que se vacía con facilidad. Por decirlo en términos de Jameson, el signo (el flequillo de los romanos) connota historia (la Roma clásica) pero denota sordera histórica (nada sabemos en realidad, viendo esa película, de la época romana). Ocurre así porque la dudosa consistencia de este tipo de signos termina haciendo que invistan más «un cierto conocimiento de lo real que lo real mismo». ${ }^{56}$ Esa es la razón de que para expresar el sentido precario que contienen hayan de utilizarse conceptos efímeros o ligados a contingencias limitadas que no siempre se encuentran en el vocabulario de nuestras lenguas. De ahí que el neologismo (la romanidad) se vuelva inevitable.

Jameson también recurre al neologismo para designar el concepto que encubren los mitos pseudohistoricistas de películas nostálgicas como American Graffiti, en la que se connota la era Eisenhower o, como él dice, los «años ciencuenta-idad», o Chinatown y El Conformista, donde relucen por el contrario «los años treinta-idad». Como Barthes, Jameson considera igualmente que estas significaciones connotativas se imponen públicamente de forma estereotipada y con escasa consistencia debido a que hacen uso de las «lustrosas cualidades de la imagen» y de la moda. ${ }^{57}$ Concluye entonces que nos encontramos, no ante un certero historicismo, sino ante la práctica eminentemente postmoderna de la intertextualidad, «un rasgo deliberado e inherente al efecto estético y que activa una nueva connotación de "antigüedad" y profundidad pseudohistórica en la que la historia de los estilos estéticos desplaza a la "verdadera" historia». ${ }^{58}$ El cine de la nostalgia, sólo aparentemente histórico, estaría, pues, constreñido por la necesidad de armonizar en un todo inverosímil el pasado con el «impe-

54 Ibid., pp. 30-31.

55 Ibid., p. 200.

56 Ibid., p. 211.

57 F. Jameson, Teorías de la postmodernidad, op. cit., pp. 40-41.

58 Ibid., p. 40. 
rio efímero» de la moda. ${ }^{59}$ Naturalmente, el resultado no puede ser otro que el pastiche.

El preponderante papel que ostenta la película nostálgica en el no muy extenso texto de Jameson y su insistencia en la melancolía o la nostalgia postmodernas deben interpretarse como una consecuencia más de la actitud desencantada que todo crítico marxista adopta ante la cultura de masas. Georg Stanth y Bryan S. Turner, que lo han estudiado en el caso de los pensadores postmodernos, han recordado que el primer tratamiento de la nostalgia en el sentido crítico de la cultura se retrotrae a la Escuela de Frankfurt, -y en última instancia a Marx${ }^{60}$ y especialmente a la crítica cultural que llevó a cabo Theodor W. Adorno. La melancolía que caracteriza al intelectual, afirman estos autores, suele ser recurrente en los pensadores de ideología marxista para quienes la cultura de masas está dominada por el capitalismo salvaje. ${ }^{61}$

$\mathrm{El}$ «paradigma nostálgico» contiene, según estos autores, cuatro componentes que podemos identificar en el texto de Jameson: en primer lugar, una noción de historia entendida como declinación o caída de una época dorada y esperanzada, justo la misma que se encuentra en La lógica cultural del capitalismo tardío cuando se reflexiona sobre la «sordera» histórica del postmodernismo. En segundo lugar, la conciencia de que los sistemas sociales modernos y sus culturas son pluralistas, secularizados y diversos, lo que implica una intensa fragmentación de las creencias y las prácticas; esta idea también se encuentra en las características que Jameson atribuye al pastiche postmoderno en su distinción con la parodia. En tercer lugar, la conciencia de estar inmersos en una pérdida de individualidad y autonomía que se diluye en proporción inversa a la extensión del engranaje de la regulación burocrática, y que tanto tiene que ver con el diagnóstico de la sociedad del espectáculo que elaboran Debord y los frankfurtianos en su denuncia de la razón instrumental. Por último, un sentido del pasado excesivamente reduccionista que promueve su consideración en términos de simplicidad, autenticidad y espontaneidad, y que es el mismo que aparece reflejado en la película nostálgica de Jameson. ${ }^{62}$

59 Tomo la expresión de G. Lipovetsky, El imperio de lo efímero. La moda y su destino en las sociedades democráticas, tr. F. Hernández y C. López. Barcelona: Anagrama, 1990.

60 De hecho, Georg Stand y Bryan S. Turner afirman que la descripción que hace Marx de las actividades del hombre socialista venidero pueden ser consideradas como una nostalgia proyectada hacia el futuro, «a forward-looking nostalgia». G. Stanth y B. Turner, «Nostalgia, Postmodernism and the Critique of Mass Culture», Theory Culture \& Society, vol. 5, Numbers 2-3, June, 1988, p. 514

61 Ibid., pp. 509.

62 Ibid. 


\section{LA EXCEPCIÓN DE LA ARQUITECTURA HISTORICISTA}

Recordemos que Jameson excluye del sentimiento postmoderno de la nostalgia a la arquitectura historicista, a la que, siguiendo la lógica del texto, tampoco se le puede considerar como un pastiche público.

Jameson sabe de sobra que el prefijo «post» alude en la arquitectura postmodernista o también llamada historicista al propósito de sus representantes de superar el modernismo arquitectónico. ${ }^{63}$ No se trata de una reacción formal, sino de una que compromete a toda la filosofía de la vanguardia que subyace al proyecto moderno desde la Bauhaus. ${ }^{64}$ El blanco de los arquitectos postmodernos es más bien su ideología racionalista, sus declaraciones en torno a la belleza funcional, o sus proclamaciones acerca de su propia necesidad y universalidad aparte de su carácter utópico. ${ }^{65}$

El prefijo «post» que encabeza su nombre viene marcado por una estética «pre», si se me permite la expresión, puesto que la principal característica que la particulariza consiste en recuperar estilística y paródicamente el pasado, no para mostrar, en paralelo con la «película nostálgica», su lamento por lo que fue, sino para expresar la idea emocionalmente neutra de que edificar constituye un gesto social, político y determinado históricamente. La arquitectura historicista recupera e ironiza el pasado porque tiene la intención de revisar lo ya dado y establecer desde ahí una relación crítica con todo un mundo discursivo de significación establecido social y políticamente. ${ }^{66}$ Linda Hutcheon o Matei Calinescu han deducido de ello que esta arquitectura desautoriza la tesis postmoderna de corte marxista que considera a la postmodernidad como una época ahistórica por cuanto la respuesta que da a las rigideces utópicas de los modernistas parece haber sido más bien exigir una ciudad moderna con memoria ${ }^{67}$

Sea como sea, es cierto que el programa ideológico de este tipo de arquitectura impide que se le califique de pastiche en el sentido que ostenta el término en el ensayo de Jameson. Pensemos, en primer lugar, que la arquitectura historicista imita ridiculizándola la del pasado, pero, puesto que sus pretensiones son revisionistas y críticas, no puede constituir, al menos teóricamente, una «parodia vacía» o una «estatua ciega».

En segundo lugar, tengamos en cuenta que la ideología que acompaña a la arquitectura historicista es muy afín a la del propio Jameson: influenciado tanto por el marxismo como por el estructuralismo, el análisis de la lógica cultural

63 Para más detalles sobre la arquitectura moderna, véase M. Calinescu, op. .cit. p. 275. 64 Ibid., p. 274.

65 Ibid.,p. 274 y L. Hutcheon, A poetics of Postmodernism. History, Theory, Fiction. New York and London: Routledge, 2005, p. 25.

66 L. Hutcheon, op. cit. p. 22.

67 Ibid., p. 87, y M. Calinescu, op. cit., p. 276. 
del capitalismo tardío saca o pretende sacar a la luz los entresijos ideológicos y económicos relacionados con un sistema de poder económico y político que el autor asocia con Estados Unidos y que subyacen a la superestructura de la postmodernidad, a su «lógica cultural». Se puede decir que la arquitectura postmoderna nace con una finalidad semejante -aunque no haya sido elaborada siempre desde los presupuestos marxistas-en tanto en cuanto trasciende también los meros formalismos para desenmascarar los resortes de poder que encubren determinadas prácticas arquitectónicas del pasado, lo que desvía la atención de la autoría o de la obra a la estructura económica, política y social que los ha dado lugar. Se podría incluso establecer una relación entre los presupuestos ideológicos de la arquitectura postmoderna y los filosóficos de algunos autores estructuralistas, como Michel Foucault, en cuya obra queda clara la idea de que el poder está unido al saber (o al hacer artístico, como sería en nuestro caso la arquitectura postmoderna), por lo que no puede considerarse como un epifenómeno o como algo instrumental, sino, nietzscheanamente hablando, como algo inherente a cada acontecimiento. ${ }^{68}$

Jameson no se fija en las particularidades formales de una arquitectura que, desde un punto de vista estético, tantas afinidades comparte con el pastiche, el collage o la intertextualidad, sino que es capaz de mirar más allá para salvaguardar así una de las prácticas postmodernas que más simpatía y afinidades ideológicas le suscita. Esa es la razón de que, pese a los parecidos formales, la arquitectura postmoderna no sea considerada en su ensayo como un ejemplo más del pastiche postmoderno.

VII. UN ARTE SIN ESTILO: EL PASTICHE Y EL DESCENTRAMIENTO DEL SUJETO

A su interpretación del pastiche, Jameson añade la idea, de influencia estructuralista, de que el pastiche carece de estilo debido a que el postmodernismo ha dejado de creer en la subjetividad. De nuevo tenemos que recordar aquí, aunque sea brevemente, las consignas establecidas por Michel Foucault, que son la referencia oculta bajo estas afirmaciones.

Como bien se ha dicho, el hilo conductor de toda su obra es la objetivación a que las prácticas discursivas y no discursivas de una determinada sociedad someten al individuo. ${ }^{69}$ La regulación de las distintas dimensiones del comportamiento humano unido a la proliferación de una amplia gama de discursos que lo objetivan (la pedagogía o la psicología, por ejemplo) hacen que los individuos sean conformados a través de instancias de conocimiento que dictan su verdad y que delimitan su identidad. Esa es la razón de que la filosofía de

68 Véase J. Álvarez Llagues, Michel Foucault: verdad, poder, subjetividad.La modernidad cuestionada. Madrid: Ediciones pedagógicas, 1996.

69 Ibid. 
Foucault renuncie a buscar la esencia de las cosas y se detenga a analizar las condiciones de posibilidad en las que se produjo el saber del hombre y a las que tanto contribuyó la emergencia de las ciencias humanas. ${ }^{70}$ Ello ha conducido a calificar su pensamiento anti-humanista como un «trascendentalismo sin sujeto trascendental» ${ }^{71}$ y a considerar que sus planteamientos son un claro exponente de las pretensiones filosóficas contemporáneas de desechar las filosofías modernas de la conciencia.

No hay que olvidar que Jameson se apropia de los presupuestos del estructuralismo en momentos determinantes de su exposición, como cuando alude al hecho de que la postmodernidad arruina el llamado «modelo de la profundidad» que ahorma los fundamentos de los esquemas dualistas modernos como el dialéctico, el freudiano, el existencial y el semiótico. ${ }^{72} \mathrm{Su}$ guiño al pensamiento francés contemporáneo no es en absoluto gratuito. Jameson acepta sus presupuestos porque le sirven para argumentar la falta de estilo que caracteriza al pastiche postmoderno, que se construiría precisamente sobre el derrumbe del modelo artístico de la profundidad, liderado por el concepto romántico de expresión, y que presupone también una escisión metafísica en el sujeto monádico y artístico entre interior y exterior. El autor se apropia y reutiliza la idea foucaultiana de la muerte del sujeto para conducirla al terreno artístico y argumentar la ausencia de subjetividad que caracteriza al pastiche postmoderno. Del texto del filósofo norteamericano, se deduce entonces que el pastiche no puede ser producto de un sujeto autónomo y constituyente -en este caso del acto creativo-, puesto que la disolución a que está sometido en una época sin sentido histórico y desprovista de fundamentos impide que podamos proyectar interpretaciones basadas en la idea de autoría o de originalidad, tan ligadas a una metafísica del interior y al paradigma hermenéutico de cariz diacrónico que le otorga medida.

Precisemos para terminar que Jameson entiende el término estilo al modo en que lo hace Meyer Shapiro, para quien constituye, más que una cuestión formal, todo un sistema de normas cualitativas repletas de expresión en las que se manifiesta la personalidad de los artistas y la filosofía de todo un grupo. ${ }^{73}$ Jameson retoma este uso del término porque, como Jan Biatostocki ha estudiado en el caso de Shapiro, se da cuenta de que está elaborado sobre un punto de vista histórico según el cual, pese a que en su origen los estilos no fueran perseguidos de manera premeditada, sus rasgos determinan finalmente las diferentes uni-

70 Véase J. Sanquillo, Para leer a Foucault. Madrid: Alianza, 2001. Véase al respecto M. Foucault, Las palabras y las cosas, tr. Elsa Cecilia Frost. Madrid: Siglo XXI, 1999.

71 J. Álvarez Llagues, op. cit.

72 F. Jameson, Teorías de la postmodernidad, op. cit., en general el apartado I.

73 M. Shapiro, «Style», en Anthropology Today. An Encyclopedic Inventory. Chicago: A.I. Kroeber, The University of Chicago Press, 1957, pp. 287-312. 
dades estéticas que especifican la ruta seguida por los artistas. ${ }^{74}$ Dicho de otra manera, el concepto de estilo es esencialmente moderno y se puede asociar a la filosofía de la historia, al paradigma de la profundidad y a la consistencia de una subjetividad artística monádica y expresiva. Su intrínseca relación con la historia, con el sujeto constituyente moderno y con una práctica artística en la que todavía tiene valor la autoría o la originalidad, convierten al concepto de «estilo» en el mejor instrumento para alumbrar por oposición una práctica que ha de entenderse como post-histórica o postmoderna, carente de subjetividad y estéticamente imitativa, fraudulenta o previsible.

La teoría del pastiche de Jameson adquiere este tono tan negativo más por cuestiones ideológicas que estéticas. La asunción del marxismo y del postestructuralismo empaña su percepción y desvía su mirada del análisis concreto de las obras. Esta actitud, digamos para terminar, sería mucho más reivindicable por cuanto evitaría el error que siempre acecha en este tipo de formulaciones: el de la injustificada generalización.

Inmaculada Murcia Serrano es Profesora Ayudante del Departamento de Estética e Historia de la Filosofía de la Universidad de Sevilla

Linea de investigación: Estética y Teoría de las Artes

Publicaciones recientes:

Inmaculada Murcia/Diego Romero de Solís/ Jorge López Lloret, Variaciones sobre el color, Secretariado de publicaciones de la Universidad de Sevilla, Sevilla, 2007, (ISBN. 97884-472-0905-7).

Inmaculada Murcia, «De Dios y lo sublime» en Anales del Instituto de Investigaciones Estéticas, Universidad Nacional Autonómica de México. Instituto de Investigaciones Estéticas, México, nº 93, 2009, pp. 137-160 (ISSN: 0185-1276)

Dirección: c/ Zurbarán, n ${ }^{25}$, Castilleja de la Cuesta (41950)

Correo electrónico: imurcia@us.es

74 Véase J. Biatostocki, Estilo e iconografía. Contribución a una ciencia de las artes, tr. J. M. Pomares. Barcelona: Barral, 1973. 
